\title{
Benzothiazolium salts as reagents for the deoxygenative perfluoroalkylthiolation of alcohols
}

\author{
Armin Ariamajd ${ }^{\ddagger}$, Nils J. Gerwien ${ }^{\ddagger}$, Benjamin Schwabe, Stefan Dix \\ and Matthew N. Hopkinson*
}

\section{Letter}

\section{Address:}

Institute of Chemistry and Biochemistry, Freie Universität Berlin,

Fabeckstrasse 34-36, 14195 Berlin, Germany

Email:

Matthew N. Hopkinson* - matthew.hopkinson@fu-berlin.de

* Corresponding author $\ddagger$ Equal contributors

Keywords:

alcohols; benzothiazolium salts; deoxygenative reactions; fluorine;

perfluoroalkylthiolation; thioethers

\author{
Beilstein J. Org. Chem. 2021, 17, 83-88. \\ https://doi.org/10.3762/bjoc. 17.8 \\ Received: 30 October 2020 \\ Accepted: 11 December 2020 \\ Published: 08 January 2021 \\ This article is part of the thematic issue "Organo-fluorine chemistry V". \\ Guest Editor: D. O'Hagan \\ (C) 2021 Ariamajd et al.; licensee Beilstein-Institut. \\ License and terms: see end of document.
}

\begin{abstract}
A series of 2-(perfluoroalkylthio)benzothiazolium $\left(B T-\mathrm{SR}_{\mathrm{F}}\right)$ salts have been synthesized that serve as convenient sources of hitherto underexplored perfluoroalkylthiolate anions. An investigation of their reactivity in a deoxygenative nucleophilic substitution reaction led to the development of an unprecedented process that provides pentafluoroethyl and heptafluoropropyl thioethers directly from readily available alcohols.
\end{abstract}

\section{Introduction}

The incorporation of fluorine-containing groups into organic molecules to modulate their biological or physical properties is nowadays a common strategy employed in the development of pharmaceuticals [1-4], agrochemicals [5] and materials [6]. Recent years have seen a surge in interest in emerging fluorinated motifs, which can offer improved performance over single fluorine atoms or perfluoroalkyl substituents. The trifluoromethylthio group $\left(\mathrm{SCF}_{3}\right)$, for example, is attracting considerable attention due to its strong lipophilicity-enhancing influence (Hansch constant $\pi=1.44$ ) and electron-withdrawing properties (Hammett constants $\sigma_{\mathrm{p}}=0.50$ and $\sigma_{\mathrm{m}}=0.40$ ) [7-12] On the other hand, longer-chain perfluoroalkylthio groups $\left(\mathrm{SR}_{\mathrm{F}}\right.$ $\mathrm{R}_{\mathrm{F}}=\mathrm{C}_{n} \mathrm{~F}_{2 n+1}$ ) have received comparatively little attention despite promising applications in liquid crystal displays [13,14], as pharmaceuticals and agrochemicals [15]. For example, analogues of the drug losartan featuring $\mathrm{SC}_{2} \mathrm{~F}_{5}, \mathrm{SC}_{3} \mathrm{~F}_{7}$ and $\mathrm{SC}_{4} \mathrm{~F}_{9}$ groups have shown promise as treatments for hypertensive disorders [16]. Furthermore, in a number of drug candidates, exchanging a $\mathrm{CF}_{3}$ group with $\mathrm{C}_{2} \mathrm{~F}_{5}$ has been shown to result in superior pharmacological properties; however, analogous studies comparing $\mathrm{SCF}_{3}$ with $\mathrm{SC}_{2} \mathrm{~F}_{5}$ are scarce [17-19].

Much of the recent interest in the $\mathrm{SCF}_{3}$ group can be attributed to the development of several bench-stable and easily handled trifluoromethylthiolating reagents, which do not require specialist equipment or expertise [7-12]. Synthetic approaches towards longer-chain perfluoroalkylthio-substituted molecules, on the other hand, remain limited. In the vast majority of cases, 
the $\mathrm{SR}_{\mathrm{F}}$ group is not installed as an intact functional group but rather indirectly through perfluoroalkylation of a thiol or sulfide moiety already present on the substrate (Scheme 1a) [15,20-26]. By contrast, direct perfluoroalkylthiolation, which avoids prefunctionalization of the substrate, has been hindered by the lack of suitable reagents. In recent years, however, a selection of mostly electrophilic and radical sources has been introduced [27]. Nucleophilic perfluoroalkylthiolation is especially challenging due to the low nucleophilicity of heavily fluorinated thiolate anions and the potential for deleterious side-reactions resulting from $\beta$-fluoride elimination [28-34]. Only a handful of perfluoroalkylthiolate salts are known and, to the best of our knowledge, only one general direct nucleophilic perfluoroalkylthiolation of an alkyl electrophile has been reported to date [35]. This process used an umpolung strategy with activation of typically electrophilic perfluoroalkylsulfenamide reagents by iodide, releasing ${ }^{-} \mathrm{SC}_{2} \mathrm{~F}_{5}$ or ${ }^{-} \mathrm{SC}_{3} \mathrm{~F}_{7}$ anions in situ, which could then react with a selection of alkyl halides (Scheme 1b).

In 2019, we reported a new reagent for nucleophilic trifluoromethylthiolation based on the benzothiazolium motif: BT-SCF 3 [36-38]. This easily handled solid, which is stable at least over several months under ambient conditions, could be engaged in efficient deoxygenative trifluoromethylthiolation reactions of readily available aliphatic alcohols. Some features of this process led us to consider whether related benzothiazolium salts featuring longer-chain $\mathrm{SR}_{\mathrm{F}}$ substituents could serve as practical reagents for investigating nucleophilic perfluoroalkylthiolation reactions. Firstly, the simple two-step synthesis of $\mathrm{BT}-\mathrm{SCF}_{3}$ from inexpensive 2-mercaptobenzothiazole (MBT) can be readily adapted to provide a wide range of different $\mathrm{BT}-\mathrm{SR}_{\mathrm{F}}$ reagents. Moreover, in situ activation of the benzothiazolium salt by the alcohol provides a highly reactive alkyl electrophile, which can compensate for the inherently low nucleophilicity of ${ }^{-} \mathrm{SR}_{\mathrm{F}}$ anions [39]. Herein, we report the successful synthesis of several $\mathrm{BT}-\mathrm{SR}_{\mathrm{F}}$ reagents and provide insights into the reactivity of different perfluoroalkylthiolate anions in nucleophilic substitution reactions. This study led to the development of unprecedented deoxygenative pentafluoroethyl- and heptafluoropropylthiolation reactions directly from alcohols (Scheme 1c).

\section{Results and Discussion}

Five $\mathrm{BT}-\mathrm{SR}_{\mathrm{F}}$ reagents were selected to provide a good overview on the reactivity of different perfluoroalkylthio groups; four linear BT-SR $\mathrm{F}_{\mathrm{F}}$ derivatives $\left(\mathrm{BT}-\mathrm{SC}_{2} \mathrm{~F}_{5}, \mathrm{BT}_{-} \mathrm{SC}_{3} \mathrm{~F}_{7}\right.$,

a) previous syntheses of perfluoroalkyl thioethers

traditional approach

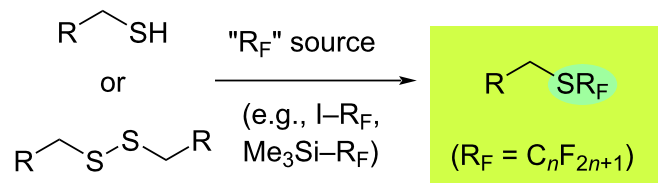

direct perfluoroalkylthiolation

"SR $\mathrm{F}_{\mathrm{F}}$ source

- - - - - - $\mathrm{R}^{\mathrm{X}} \mathrm{X}$

few examples few perfluoroalkylthiolating reagents known

$\Rightarrow$ nucleophilic methods hindered by low nucleophilicity of ${ }^{-} \mathrm{SR}_{\mathrm{F}}$ and potential $\beta$-fluoride elimination

b) nucleophilic perfluoroalkylthiolation of alkyl halides via an umpolung strategy (Billard [35])

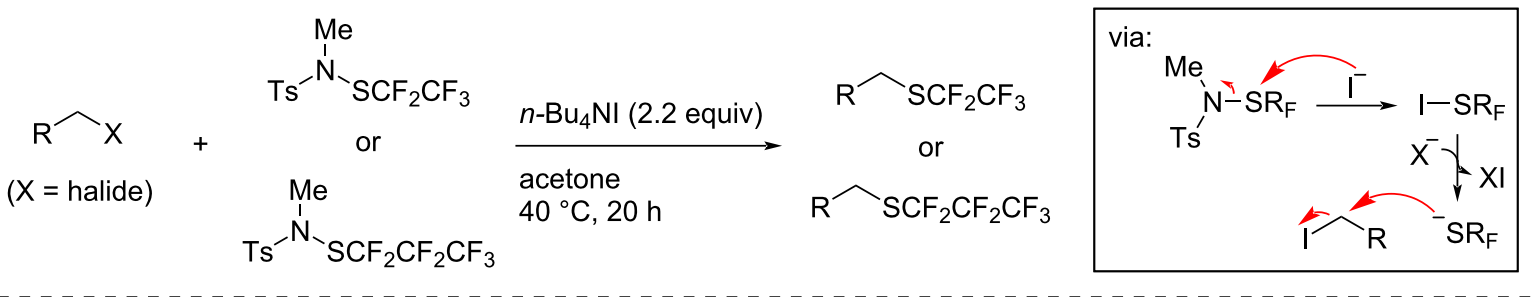

c) this work: deoxygenative perfluoroalkylthiolation of alcohols using BT-SR $\mathrm{F}_{\mathrm{F}}$ reagents

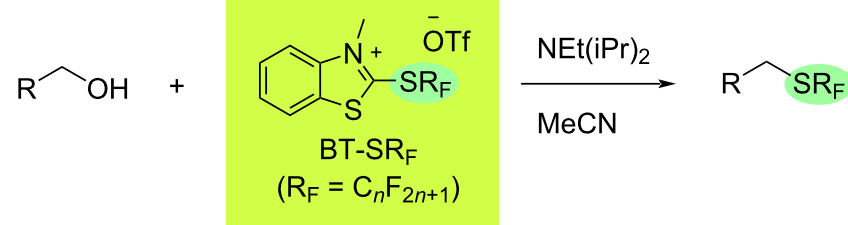

$B T-S R_{F}$ reagents as new, easily prepared sources of ${ }^{-} \mathrm{SR}_{\mathrm{F}}$ anions

In situ generation of reactive electrophile compensates for low nucleophilicity of ${ }^{-} \mathrm{SR}_{\mathrm{F}}$

synthesis of perfluoroalkyl thioethers directly from readily available alcohols 
BT-SC ${ }_{5} \mathrm{~F}_{11}$ and $\left.\mathrm{BT}_{-} \mathrm{SC}_{8} \mathrm{~F}_{17}\right)$ and the perfluoroisopropyl species $\mathrm{BT}-\mathrm{SCF}\left(\mathrm{CF}_{3}\right)_{2}$. Each reagent was synthesized according to the two-step procedure shown in Scheme 2. Firstly, MBT was reacted with a perfluoroalkyl iodide and $\mathrm{NaH}$ in DMF under irradiation with UVA LEDs $\left(\lambda_{\max }=365 \mathrm{~nm}\right)$. In all cases, efficient $S$-perfluoroalkylation was observed within $16 \mathrm{~h}$ at $\mathrm{rt}$, and the heteroaromatic compounds 1a-e could be isolated in good yields. Subsequent $\mathrm{N}$-methylation with methyl trifluoromethanesulfonate in $\mathrm{CH}_{2} \mathrm{Cl}_{2}$ also proceeded smoothly with the BT-SR $\mathrm{F}_{\mathrm{F}}$ reagents each being obtained after $48 \mathrm{~h}$ at $\mathrm{rt}$ in high yields upon precipitation with $\mathrm{Et}_{2} \mathrm{O}$. As with $\mathrm{BT}-\mathrm{SCF}_{3}$, further purification of the reagents was not required and each was found to be stable at least over several months when stored in a fridge.

With a selection of BT-SR $\mathrm{F}_{\mathrm{F}}$ reagents in hand, we next sought to evaluate their relative reactivity in a benchmark nucleophilic perfluoroalkylthiolation. Thus, 4-nitrobenzyl alcohol (2a) was reacted with 1.25 equivalents of $\mathrm{BT}-\mathrm{SC}_{2} \mathrm{~F}_{5}$ and 2 equivalents of $\mathrm{NEt}(\mathrm{iPr})_{2}$ in $\mathrm{MeCN}$ for $2 \mathrm{~h}$ at rt. The analysis of the crude reac- tion mixture by NMR revealed the formation of two products: the desired (pentafluoroethyl) thioether 3a in 78\% NMR yield and a second species with ${ }^{19} \mathrm{~F}$ and ${ }^{1} \mathrm{H}$ spectra consistent with the trifluoromethyl thionoester 4a (7\% NMR yield, Table 1, entry 1). The formation of both species can be explained by the mechanism shown in Scheme 3 [36]. Nucleophilic attack of the alcohol in the presence of $\mathrm{NEt}(\mathrm{iPr})_{2}$ at the $\mathrm{C} 2$-position of the BT reagent affords the key electrophilic 2-alkoxybenzothiazolium species A and the perfluoroalkylthiolate anion. Nucleophilic substitution then affords product $\mathbf{3}$ and thiocarbamate byproduct $\mathbf{B}$. As a side-reaction, $\beta$-fluoride elimination from the perfluoroalkylthiolate anion can occur, leading to a thiocarbonyl fluoride species, which can subsequently react with the alcohol, delivering thionoester 4. $\beta$-Fluoride elimination is a known decomposition pathway of ${ }^{-} \mathrm{SCF}_{3}$ and has even been exploited in synthetic trifluoromethylthiolation and fluorination processes [32-34].

The formation of the side-product 4 a could be effectively suppressed by conducting the reaction at $-40{ }^{\circ} \mathrm{C}$. Under these

\begin{tabular}{|c|c|c|c|c|c|c|}
\hline \multirow{7}{*}{ MBT } & \multirow{3}{*}{$\begin{array}{l}\mathrm{R}_{\mathrm{F}} \mathrm{I}(1.2-2.0 \text { equiv) } \\
\mathrm{NaH}(1.1 \text { equiv) } \\
\mathrm{DMF}, \mathrm{rt} \\
\text { UVA LEDs } \\
\left(\lambda_{\max }=365 \mathrm{~nm}\right)\end{array}$} & \multirow{7}{*}{$\begin{array}{l}\text { 1a }\left(\mathrm{R}_{\mathrm{F}}=\mathrm{CF}_{2} \mathrm{CF}_{3}\right) \\
\mathbf{1} \mathbf{b}\left(\mathrm{R}_{\mathrm{F}}=\mathrm{CF}_{2} \mathrm{CF}_{2} \mathrm{CF}_{3}\right) \\
\mathbf{1 c}\left(\mathrm{R}_{\mathrm{F}}=\mathrm{CF}_{2}\left(\mathrm{CF}_{2}\right)_{3} \mathrm{CF}_{3}\right) \\
\text { 1d }\left(\mathrm{R}_{\mathrm{F}}=\mathrm{CF}_{2}\left(\mathrm{CF}_{2}\right)_{6} \mathrm{CF}_{3}\right) \\
\text { 1e }\left(\mathrm{R}_{\mathrm{F}}=\mathrm{CF}\left(\mathrm{CF}_{3}\right)_{2}\right)\end{array}$} & & \multirow{2}{*}{$\frac{\text { MeOTf (2.2-3.0 equiv) }}{\mathrm{CH}_{2} \mathrm{Cl}_{2}, \mathrm{rt}, 48 \mathrm{~h}}$} & \multicolumn{2}{|c|}{${ }_{N}^{\prime}+{ }^{-}$OTf } \\
\hline & & & & & & \\
\hline & & & $61 \%$ & & $\mathrm{BT}_{-} \mathrm{SC}_{2} \mathrm{~F}_{5}$ & $91 \%$ \\
\hline & & & $79 \%$ & & $\mathrm{BT}-\mathrm{SC}_{3} \mathrm{~F}_{7}$ & $94 \%$ \\
\hline & & & $69 \%$ & & $\mathrm{BT}-\mathrm{SC}_{5} \mathrm{~F}_{11}$ & $94 \%$ \\
\hline & & & $95 \%$ & & $\mathrm{BT}-\mathrm{SC}_{8} \mathrm{~F}_{17}$ & $92 \%$ \\
\hline & & & $91 \%$ & & $\mathrm{BT}-\mathrm{SCF}\left(\mathrm{CF}_{3}\right)_{2}$ & $83 \%$ \\
\hline
\end{tabular}

Scheme 2: Two-step synthesis of BT-SR $R_{F}$ reagents from MBT.

Table 1: Deoxygenative perfluoroalkylthiolation of alcohol 2a with BT-SR reagents. $^{\text {a }}$

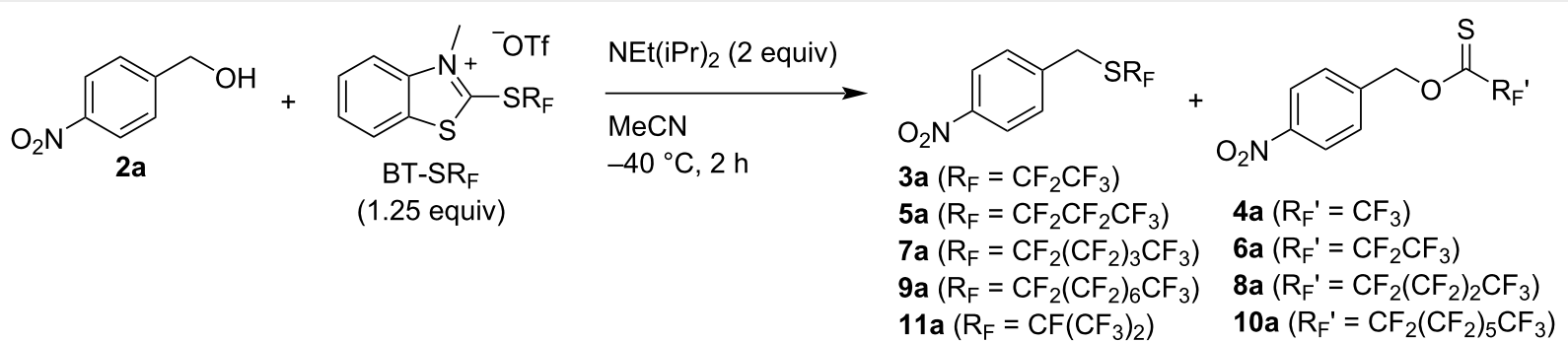

\begin{tabular}{llll}
\hline Entry & $\mathrm{R}_{\mathrm{F}}$ & ${ }^{1} \mathrm{H}$ NMR yield of thioether & 1 $\mathrm{H}$ NMR yield of thionoester \\
\hline $1^{\mathrm{b}}$ & $\mathrm{CF}_{2} \mathrm{CF}_{3}$ & $\mathbf{3 a}(78 \%)$ & $\mathbf{4 a}(7 \%)$ \\
2 & $\mathrm{CF}_{2} \mathrm{CF}_{3}$ & $\mathbf{3 a}(99 \%)$ & $\mathbf{4 a}($ trace $)$ \\
3 & $\mathrm{CF}_{2} \mathrm{CF}_{2} \mathrm{CF}_{3}$ & $\mathbf{5 a}(82 \%)$ & $\mathbf{6 a}(15 \%)$ \\
4 & $\mathrm{CF}_{2}\left(\mathrm{CF}_{2}\right)_{3} \mathrm{CF}_{3}$ & $\mathbf{7 a}(74 \%)$ & $\mathbf{8 a}(26 \%)$ \\
5 & $\mathrm{CF}_{2}\left(\mathrm{CF}_{2}\right)_{6} \mathrm{CF}_{3}$ & $\mathbf{9 a}(46 \%)$ & $\mathbf{1 0 a}(47 \%)$ \\
6 & $\mathrm{CF}\left(\mathrm{CF}_{3}\right)_{2}$ & $\mathbf{1 1 a}(\operatorname{trace})$ & - \\
\hline
\end{tabular}

aReaction conditions: $\mathrm{BT}^{-S R_{\mathrm{F}}}$ (1.25 equiv), $\mathrm{NEt}(\mathrm{iPr})_{2}\left(2\right.$ equiv), $\mathrm{MeCN}(0.17 \mathrm{M}),-40{ }^{\circ} \mathrm{C}, 2 \mathrm{~h}$. ${ }^{\mathrm{b}}$ Reaction conducted at rt. 


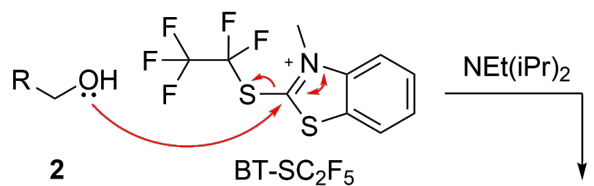<smiles></smiles>

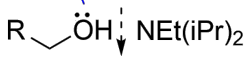<smiles>[R]COC(=S)C(F)(F)F</smiles><smiles>[R]CSC(F)(F)C(F)(F)F</smiles>

$\downarrow S_{N}$

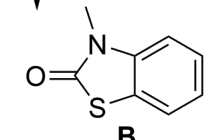

B

Scheme 3: Plausible mechanism for the formation of thioether $\mathbf{3}$ and thionoester 4.

conditions, the desired (pentafluoroethyl) thioether 3a was obtained in $99 \%$ NMR yield (91\% isolated yield, Table 1, entry 2 ). At this stage, we were ready to evaluate the relative efficiency of different perfluoroalkylthiolate nucleophiles. Each of the other BT-SR $\mathrm{F}_{\mathrm{F}}$ reagents (1.25 equiv) was reacted with alcohol $\mathbf{2 a}$ and $\mathrm{NEt}(\mathrm{iPr})_{2}$ (2 equiv) in $\mathrm{MeCN}$ at $-40{ }^{\circ} \mathrm{C}$ and, after $2 \mathrm{~h}$, the crude mixture was analysed by ${ }^{1} \mathrm{H}$ and ${ }^{19} \mathrm{~F}$ NMR. As shown in Table 1, a significant decrease in the nucleophilic perfluo- roalkylthiolation efficiency was observed upon increasing the $\mathrm{R}_{\mathrm{F}}$ chain length (Table 1, entries 2-5). For example, thionoester 8a was generated as a significant side product $(26 \%$ NMR yield) when using BT-SC $5 \mathrm{~F}_{11}$, while thioether 9a and thionoester 10a were provided in almost equal amounts when BT-SC $\mathrm{S}_{8} \mathrm{~F}_{17}$ was reacted with 2a. The increased prevalence of the $\beta$-fluoride elimination pathway with longer perfluoroalkylthio chains likely reflects the lower nucleophilicity of the increasingly fluorinated thiolate anions. Moreover, (perfluoroisopropyl) thioether 11a was produced in only trace amounts in the reaction with BT-SCF $\left(\mathrm{CF}_{3}\right)_{2}$, which is consistent with the expected lower nucleophilicity of the sterically more encumbered anion (Table 1, entry 6).

The efficient perfluoroalkylthiolation of $\mathbf{2 a}$ observed with $\mathrm{BT}-\mathrm{SC}_{2} \mathrm{~F}_{5}$ led us to further investigate this approach as a route towards (pentafluoroethyl) thioethers. Deoxygenative substitution reactions of this type are synthetically appealing as they avoid pre-generation of an active electrophile such as an alkyl halide.

A selection of benzylic alcohols 2 was reacted under the standard conditions with $\mathrm{BT}-\mathrm{SC}_{2} \mathrm{~F}_{5}$ (1.25 equiv) and $\mathrm{NEt}(\mathrm{iPr})_{2}$ ( 2 equiv) in $\mathrm{MeCN}$ at $-40{ }^{\circ} \mathrm{C}$, providing the corresponding (pentafluoroethyl) thioethers 3 in generally high yields

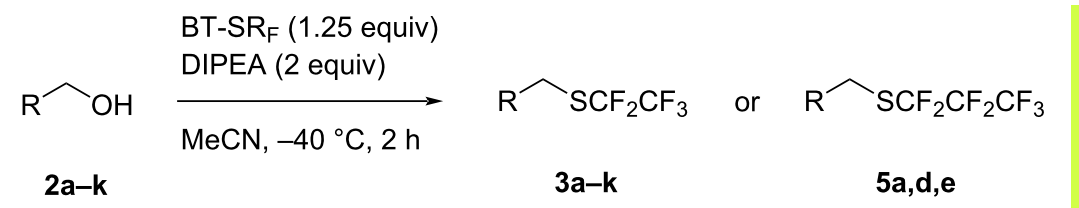

pentafluoroethylthiolation (with $\mathrm{BT}-\mathrm{SC}_{2} \mathrm{~F}_{5}$ )<smiles>O=[N+]([O-])c1ccc(CSC(F)(F)F)cc1</smiles>

3a $91 \%$<smiles>FC(F)(F)C(F)(F)C(F)(F)C(F)(F)F</smiles>

3e $90 \%$<smiles>FC(F)(F)[Se]CC#Cc1ccccc1</smiles>
heptafluoropropylthiolation (with $\mathrm{BT}-\mathrm{SC}_{3} \mathrm{~F}_{7}$ )<smiles>O=[N+]([O-])c1ccc(CSC(F)(F)C(F)(F)F)cc1</smiles>

5a $82 \%$<smiles>FC(F)(F)C(F)(F)F</smiles>
3b $73 \%$<smiles>CC(C)(C)c1ccc(CSC(F)(F)C(F)(F)F)cc1</smiles><smiles>FC(F)(F)[Se]CC=Cc1ccccc1</smiles>
3j $13 \%$<smiles>FC(F)(F)C(F)(F)C(F)(F)F</smiles>

3c $76 \%$<smiles>COC(=O)c1ccc(CSC(F)(C(F)(F)F)C(F)(F)F)cc1</smiles><smiles></smiles>

$\mathrm{BT}-\mathrm{SC}_{2} \mathrm{~F}_{5}\left(\mathrm{R}_{\mathrm{F}}=\mathrm{CF}_{2} \mathrm{CF}_{3}\right)$ 
(Scheme 4). A wide range of functional groups were tolerated, including the halogens $\mathrm{Cl}, \mathrm{Br}$, and $\mathrm{I}$, thus opening the door for further functionalization of the products via cross-coupling. The propargylic alcohol substrate $\mathbf{2 i}$ could also be converted into thioether $\mathbf{3 i}$ in $81 \%$ yield, although the allylic alcohol $\mathbf{2} \mathbf{j}$ was less efficient ( $13 \%$ yield of $\mathbf{3 j}$ ). The primary aliphatic (pentafluoroethyl) thioether $\mathbf{3 k}$ could also be obtained in the reaction between alcohol $2 \mathbf{k}$ and $\mathrm{BT}-\mathrm{SC}_{2} \mathrm{~F}_{5}$, however, with this less activated substrate, the thionoester $\mathbf{4 k}$ was generated as a significant side product. Finally, the suitability of this methodology for the preparation of (heptafluoropropyl) thioethers was investigated by reacting a selection of benzylic alcohols 2 with $\mathrm{BT}-\mathrm{SC}_{3} \mathrm{~F}_{7}$. As for the pentafluoroethylthiolation reactions, efficient conversion was observed with products 5 being obtained in high yields of up to $98 \%$.

\section{Conclusion}

In conclusion, a series of bench-stable and easy to handle 2-(perfluoroalkylthio)benzothiazolium (BT-SR ) salts have been synthesized and investigated as reagents for the direct nucleophilic perfluoroalkylthiolation of aliphatic alcohols. While $\beta$-fluoride elimination was a significant side reaction with longer-chain $\mathrm{SR}_{\mathrm{F}}$ groups, efficient deoxygenative functionalization was observed with $\mathrm{BT}-\mathrm{SC}_{2} \mathrm{~F}_{5}$ and $\mathrm{BT}-\mathrm{SC}_{3} \mathrm{~F}_{7}$. This synthetically attractive reaction provides pentafluoroethyl and heptafluoropropyl thioethers directly from readily available alcohols, thus avoiding the pre-formation of an alkyl halide. This straight-forward route should inspire further investigations of perfluoroalkylthio groups in pharmaceutical, agrochemical and materials science.

\section{Supporting Information}

The Supporting Information contains experimental procedures, characterization data of all $\mathrm{BT}-\mathrm{SR}_{\mathrm{F}}$ reagents and isolated products as well as copies of NMR spectra.

\section{Supporting Information File 1}

Experimental section.

[https://www.beilstein-journals.org/bjoc/content/

supplementary/1860-5397-17-8-S1.pdf]

\section{Acknowledgements}

We would like to acknowledge the assistance of the Core Facility BioSupraMol supported by the DFG.

\section{Funding}

Funded by the Daimler und Benz Stiftung (Postdoctoral Scholarship, Project No.: 32-04/18) and the Deutsche Forschungsgemeinschaft (DFG, German Research Foundation) - Project-
ID 387284271 - SFB 1349 (gefördert durch die Deutsche Forschungsgemeinschaft (DFG) - Projektnummer 387284271 SFB 1349)). Financial support from the Fonds der Chemischen Industrie (Sachkostenzuschuss) is also gratefully acknowledged.

\section{ORCID ${ }^{\circledR}$ iDs}

Armin Ariamajd - https://orcid.org/0000-0003-1563-6987 Nils J. Gerwien - https://orcid.org/0000-0003-2211-4829 Matthew N. Hopkinson - https://orcid.org/0000-0002-0183-0466

\section{References}

1. Müller, K.; Faeh, C.; Diederich, F. Science 2007, 317, 1881-1886. doi:10.1126/science.1131943

2. Purser, S.; Moore, P. R.; Swallow, S.; Gouverneur, V. Chem. Soc. Rev. 2008, 37, 320-330. doi:10.1039/b610213c

3. Wang, J.; Sánchez-Roselló, M.; Aceña, J. L.; del Pozo, C.; Sorochinsky, A. E.; Fustero, S.; Soloshonok, V. A.; Liu, H. Chem. Rev. 2014, 114, 2432-2506. doi:10.1021/cr4002879

4. Gillis, E. P.; Eastman, K. J.; Hill, M. D.; Donnelly, D. J.; Meanwell, N. A. J. Med. Chem. 2015, 58, 8315-8359. doi:10.1021/acs.jmedchem.5b00258

5. Fujiwara, T.; O'Hagan, D. J. Fluorine Chem. 2014, 167, 16-29. doi:10.1016/j.jfluchem.2014.06.014

6. Berger, R.; Resnati, G.; Metrangolo, P.; Weber, E.; Hulliger, J. Chem. Soc. Rev. 2011, 40, 3496-3508. doi:10.1039/c0cs00221f

7. Xu, X.-H.; Matsuzaki, K.; Shibata, N. Chem. Rev. 2015, 115, 731-764. doi:10.1021/cr500193b

8. Barata-Vallejo, S.; Bonesi, S.; Postigo, A. Org. Biomol. Chem. 2016, 14, 7150-7182. doi:10.1039/c6ob00763e

9. Xiong, H.-Y.; Pannecoucke, X.; Besset, T. Chem. - Eur. J. 2016, 22 16734-16749. doi:10.1002/chem.201603438

10. Pannecoucke, X.; Besset, T. Org. Biomol. Chem. 2019, 17, 1683-1693. doi:10.1039/c8ob02995d

11. Mampuys, P.; McElroy, C. R.; Clark, J. H.; Orru, R. V. A.; Maes, B. U. W. Adv. Synth. Catal. 2020, 362, 3-64. doi:10.1002/adsc.201900864

12. Xiao, X.; Zheng, Z.-T.; Li, T.; Zheng, J.-L.; Tao, T.; Chen, L.-M.; Gu, J.-Y.; Yao, X.; Lin, J.-H.; Xiao, J.-C. Synthesis 2020, 52, 197-207. doi:10.1055/s-0039-1690714

13. Hein, M.; Miethchen, R.; Schwäbisch, D. J. Fluorine Chem. 1999, 98 55-60. doi:10.1016/s0022-1139(99)00076-7

14. Miethchen, R.; Hein, M. Carbohydr. Res. 2000, 327, 169-183. doi:10.1016/s0008-6215(99)00317-1

15. Boiko, V. N. Beilstein J. Org. Chem. 2010, 6, 880-921. doi:10.3762/bjoc.6.88

16. Yagupolskii, L. M.; Maletina, I. I.; Petko, K. I.; Fedyuk, D. V.; Handrock, R.; Shavaran, S. S.; Klebanov, B. M.; Herzig, S. J. Fluorine Chem. 2001, 109, 87-94. doi:10.1016/s0022-1139(01)00382-7

17. Andrzejewska, M.; Yépez-Mulia, L.; Cedillo-Rivera, R.; Tapia, A.; Vilpo, L.; Vilpo, J.; Kazimierczuk, Z. Eur. J. Med. Chem. 2002, 37, 973-978. doi:10.1016/s0223-5234(02)01421-6

18. Johansson, A.; Poliakov, A.; Åkerblom, E.; Wiklund, K.; Lindeberg, G.; Winiwarter, S.; Danielson, U. H.; Samuelsson, B.; Hallberg, A. Bioorg. Med. Chem. 2003, 11, 2551-2568. doi:10.1016/s0968-0896(03)00179-2

19. Lishchynskyi, A.; Grushin, V. V. J. Am. Chem. Soc. 2013, 135, 12584-12587. doi:10.1021/ja407017j 
20. Umemoto, T.; Kuriu, Y. Chem. Lett. 1982, 11, 65-66. doi:10.1246/cl.1982.65

21. Wakselman, C.; Tordeux, M. J. Org. Chem. 1985, 50, 4047-4051. doi:10.1021/jo00221a017

22. Boiko, V. N.; Shchupak, G. M. J. Fluorine Chem. 1994, 69, 207-212. doi:10.1016/0022-1139(94)03132-0

23. Roques, N. J. Fluorine Chem. 2001, 107, 311-314. doi:10.1016/s0022-1139(00)00374-2

24. Exner, B.; Bayarmagnai, B.; Matheis, C.; Goossen, L. J. J. Fluorine Chem. 2017, 198, 89-93. doi:10.1016/j.jfluchem.2016.12.006

25. Xiang, J.-X.; Xu, X.-H.; Qing, F.-L. J. Fluorine Chem. 2017, 203 , 110-114. doi:10.1016/j.jfluchem.2017.07.008

26. Luo, Z.; Yang, X.; Tsui, G. C. Org. Lett. 2020, 22, 6155-6159. doi:10.1021/acs.orglett.0c02235

27. Baert, F.; Colomb, J.; Billard, T. Angew. Chem., Int. Ed. 2012, 51, 10382-10385. doi:10.1002/anie.201205156

28. Alazet, S.; Billard, T. Synlett 2015, 26, 76-78. doi:10.1055/s-0034-1379501

29. Jiang, L.; Qian, J.; Yi, W.; Lu, G.; Cai, C.; Zhang, W. Angew. Chem., Int. Ed. 2015, 54, 14965-14969. doi:10.1002/anie.201508495

30. Xu, B.; Li, D.; Lu, L.; Wang, D.; Hu, Y.; Shen, Q. Org. Chem. Front. 2018, 5, 2163-2166. doi:10.1039/c8qo00327k

31. Matheis, C.; Bayarmagnai, B.; Jouvin, K.; Goossen, L. J. Org. Chem. Front. 2016, 3, 949-952. doi:10.1039/c6qo00194g

32. Haszeldine, R. N.; Kidd, J. M. J. Chem. Soc. 1955, 3871-3880. doi:10.1039/jr9550003871

33. Liu, J.-B.; Xu, X.-H.; Chen, Z.-H.; Qing, F.-L. Angew. Chem., Int. Ed. 2015, 54, 897-900. doi:10.1002/anie.201409983

34. Scattolin, T.; Pu, M.; Schoenebeck, F. Chem. - Eur. J. 2018, 24 , 567-571. doi:10.1002/chem.201705240

35. Glenadel, Q.; Bordy, M.; Alazet, S.; Tlili, A.; Billard, T. Asian J. Org. Chem. 2016, 5, 428-433. doi:10.1002/ajoc.201600003

36. Dix, S.; Jakob, M.; Hopkinson, M. N. Chem. - Eur. J. 2019, 25 , 7635-7639. doi:10.1002/chem.201901607

37. Hopkinson, M.; Dix, S. Fluorine-containing compounds for use as nucleophilic reagents for transferring functional groups onto high value organic compounds. Eur. Pat. Appl. EP19150201, Jan 3, 2019. International Pat. Appl. PCT/EP2020/050031, Jan 2, 2020.

38. Tironi, M.; Maas, L. M.; Garg, A.; Dix, S.; Götze, J. P.; Hopkinson, M. N. Org. Lett. 2020, 22, 8925-8930. doi:10.1021/acs.orglett.0c03328

39. Mukaiyama, T. Angew. Chem., Int. Ed. Engl. 1979, 18, 707-721. doi:10.1002/anie.197907073

\section{License and Terms}

This is an Open Access article under the terms of the Creative Commons Attribution License (https://creativecommons.org/licenses/by/4.0). Please note that the reuse, redistribution and reproduction in particular requires that the author(s) and source are credited and that individual graphics may be subject to special legal provisions.

The license is subject to the Beilstein Journal of Organic Chemistry terms and conditions: (https://www.beilstein-journals.org/bjoc/terms)

The definitive version of this article is the electronic one which can be found at:

https://doi.org/10.3762/bjoc.17.8 